\title{
LUMBAR DISC HERNIATION: EARLY SURGERY VERSUS PROLONGED CONSERVATIVE TREATMENT.
}

1. FCPS

Fellow of Neurosurgery

Dow University of Health Sciences, Civil Hospital Karachi.

2. FCPS

Assistant Professor Neurosurgery Dow University of Health Sciences, Civil Hospital Karachi.

3. FCPS

Assistant Professor Neurosurgery Dow University of Health Sciences, Civil Hospital Karachi.

4. FCPS

Professor of Neurosurgery

Dow University of Health Sciences Civil Hospital Karachi.

5. FCPS

Assistant Professor Neurosurgery Dow University of Health Sciences, Civil Hospital Karachi.

6. FCPS

Assistant Professor Neurosurgery Dow University of Health Sciences, Civil Hospital Karachi.

7. FCPS

Professor of Neurosurgery

Dow University of Health Sciences,

Civil Hospital Karachi.

Correspondence Address

Dr. Muhammad Faiq Ali

Department of Neurosurgery

Dow University of Health Sciences

Civil Hospital Karachi.

salamfaiq@hotmail.com

Article received on:

22/02/2019

Accepted for publication:

09/04/2020

\section{INTRODUCTION}

Sciatica is a form of leg pain, with or without focal neurological deficit, radiating down the leg $^{1}$ on one or both sides. Its prevalence, as reported in literature, varies from 1.6 to $43 \% .^{2,3}$ In most of cases, sciatica is due to herniation of disc leading to nerve root compression. However, other possible causes include lumbar canal stenosis or foraminal stenosis and less often tumors or cyst. ${ }^{3,4}$ Lumbar disc herniation is protrusion of nucleus pulposus and annulus fibrosus far away from intervertebral disc space. Peak prevalence is between ages of 30-50 years with male to female ratio of $2: 1 .{ }^{5}$
Urooj Fatimah Siddiqui ${ }^{1}$, Muhammad Faiq Ali², Muhammad Asim Khan Rehmani ${ }^{3}$, Atiq Ahmed Khan ${ }^{4}$, Sheeraz Ahmed Ghori ${ }^{5}$, Qazi Muhammad Zeeshan ${ }^{6}$, M. Imran ${ }^{7}$

RACT... We seek to compare pain sensation after surgical and conservative treatment in Control Trial. Setting: Department of Neurosurgery, Dow University of Health Sciences, Civil Karachi. Period: Aug 1, 2017 till May 31, 2018. Material \& Methods: Data was

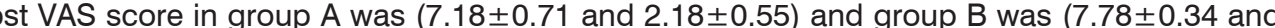
conservative treatment of sciatica, despite of pain but given the results of this study, early surgical Key words: $\quad$ Early Surgical Intervention, Prolonged Conservative Treatment, Sciatica, Visual Analogue Score.

Article Citation: Siddiqui UF, Ali MF, Rehmani MAK, Khan AA, Ghori SA, Zeeshan QM, Imran M. Lumbar disc herniation: Early surgery versus prolonged conservative treatment. Professional Med J 2020; 27(9):1784-1789. DOI: 10.29309/TPMJ/2020.27.09.3309

Management of sciatica is variable considerably. In many patients spell of low back pain resolve spontaneously in approximately $25-58 \%$ of cases, even with herniated discs. Hence, non-surgical approach is the prior step in its management. ${ }^{6}$ Duration varies from 3 to 6 months. Conservative treatment includes analgesics, physiotherapy and life style modifications. If symptoms persist or worsen, then patient eventually undergo surgery, after necessary imaging requirements (MRI). ${ }^{2}$ Surgical intervention is indicated if lumbar disc herniation is causing intractable pain or patient is having progressive focal neurological deficits and MRI findings are consistent with clinical findings of patient. ${ }^{2}$ The type of surgery 
performed are standard open discectomies or micro discectomies with or without operating microscope. Minimally invasive techniques include endoscopic discectomies.

Jo Jordan et al in a systematic review suggested that herniated portion of disc regresses in 6 months partially or completely in two-third of patients with conservative treatment. However in this review, one of RCT showed baseline VAS of two groups i.e. early surgical intervention versus prolonged conservative treatment as 67.2 vs. 64.4. After surgery vs. treatment, VAS was 10.2 vs. 27.9 and difference in mean change came out to be 57 vs. 36.5. In similar review, baseline SF36 BP of early surgical intervention versus prolonged conservative treatment was 21.9 vs. 23.9. After surgery vs. treatment, BP was 62.8 vs. 54.4 and difference in mean change was 40.9 vs. 30.55. Kovacs et al in a systematic review of 5 RCTs showed that early decompressive surgeries resulted in good outcome. In one of its RCT, Patient's global assessment showed good result with surgery as $73.1 \%$ vs. $35.9 \%$ in control group (Zuckerman et al). Difference in mean change for SF36 Bodily Pain (BP) was 17.8 (12.5 to 23) vs.1.5 (-4.2 to 7.3), (Weinstein et al), thus favoring surgery. ${ }^{7}$ Jon D Lurie et al in SPORT study demonstrated that mean change for early surgery versus non-operative treatment in BP was 42 (2) vs. $38.2(2){ }^{8}$

Vincent JA et al in a literature review showed that optimal timing for surgery is between $4 \& 8$ weeks after radicular symptoms. ${ }^{9}$ Regarding outcome of lumbar disc surgery, study was conducted by Mahsa $\mathrm{S}$, in which VAS reported as a whole 93.3\% favorable results for decreased in sciatic pain. ${ }^{10}$ MichielBlequin et al in a RCT concluded that in selected cases, conservative treatment might provide a possibility of reducing pain and disability without undergoing surgery, but with a persistent risk of delayed surgery if there is failure of prolonged conservative treatment.

Furthermore outcome of treatment with respect to timing of intervention or prolonged conservative care has not been previously evaluated properly. In spite of several randomized controlled trials
(RCTs) that have been published that have compared the effectiveness of early surgery versus prolonged conservative treatment, there is still ambiguity in its definitive management. On literature search, it is also noted that data regarding surgical versus conservative management for this problem in our population is limited. Consensus regarding early surgical intervention for sciatica has not been established.

Due to variation in genetic, geographic and demographic basis, there is better need to assess the better treatment modality with good outcome for our population. Therefore it provides strong reason to the study as our primary aim is to simultaneously compare the clinical outcome of early surgery versus prolonged conservative treatment, in order to identify the best possible treatment for reducing morbidity and sufferings of patients with sciatica to improve the quality of life.

\section{OBJECTIVE}

To compare the outcome of early surgical intervention versus prolonged conservative treatment in patients with sciatica due to herniated lumbar intervertebral discs.

\section{MATERIAL \& METHODS}

This was a Randomized Control Trial (Randomization through sealed envelope technique).

The Study was conducted at Department of Neurosurgery, Dow University of Health Sciences, Civil Hospital Karachi during Ten months, starting from 01-08-17 till 31-05-18.

By using open EPI sample size calculator, taking statistics for bodily pain score (BP) in group $A$ as 40.9 (14.5) and in group B as 30.5 (16.1), power to test as $80 \%$, with confidence interval $95 \%$, the calculated sample size will be 35 in each group5. Total sample size will be 70 .

SAMPLING TECHNIQUE: Non Probability consecutive sampling.

Patients, between 25-50 years, who presented with radicular leg pain and a positive SLR with 
duration of symptoms $<4$ weeks having herniated intervertebral disc at any of L4-S1 level, diagnosed on MRI, were included in this study.

Patients with known co-morbids (like DM, IHD, HTN), degenerative spine (like listhesis), infective pathology (like Pott's disease), spinal tumors, recurrent cases, cauda equina syndrome and traumatic/pathological fractures, were excluded from this study.

\section{Mean change in visual analog scale (VAS)}

VAS comprises of a horizontal line of $10 \mathrm{~cm} / 100 \mathrm{~mm}$ and it is divided into segments with sequential labels; 0 (no pain) to 10 (worst pain). Patient is asked to mark his pain level on it.

In this study, mean pain score (VAS) will be recorded before intervention/therapy (baseline) and then on 10th day after surgery/completion of therapy. Outcome will be measured as difference in mean change of pain score (VAS).

\section{Mean change in SF36 bodily pain (BP)}

Lower scores mean more disability, higher scores mean less disability 12 .

In this study, we will include bodily pain (BP) score to assess outcome of early surgical intervention vs. prolonged conservative treatment. BP has 2 questions. Each question has a score and after averaging these scores they are charted on scale.

Mean pain score (BP) will be recorded before intervention/therapy (baseline) and then on 10th day after surgery/completion of therapy. Outcome will be measured as difference in mean change of pain score (BP).

\section{RESULTS}

A total of 70 patients, diagnosed as sciatica due to herniated intervertebral disc, visited Department of Neurosurgery, Dow University of Health Sciences, Civil Hospital Karachi and met the inclusion and exclusion criteria of this study.

Out of 35 patients in group A, minimum age of the patient was 32 while maximum age of the patients was 54 years. Mean age in our study was 45.18 years with the standard deviation of \pm 7.64 . Mean duration of sciatica symptoms in our study was $2.78 \pm 0.78$ weeks. Similarly, out of 35 patients in group B minimum age of the patient was 32 while maximum age of the patients was 54 years. Mean age in our study was 42.78 years with the standard deviation of \pm 5.87 . Mean duration of sciatica symptoms in our study was $3.26 \pm 0.51$ weeks.

Out of 35 patients in group A mean pre and post VAS score in our study was $7.18 \pm 0.71$ and $2.18 \pm 0.55$ respectively. Similarly, out of 35 patients in group B mean pre and post VAS score in our study was $7.78 \pm 0.34$ and $3.26 \pm 0.21$ respectively. P-value was 0.12 . As shown in Table-l.

\begin{tabular}{|l|c|c|c|}
\hline \multicolumn{1}{|c|}{ Variable } & Mean & $\begin{array}{r}\text { Standard } \\
\text { Deviation }\end{array}$ & P-Value \\
\hline Pre-vas score in group A & 7.18 & \pm 0.71 & \\
\hline Post-vas score in group A & 2.18 & \pm 0.55 & \multirow{2}{*}{0.12} \\
\hline Pre-vas score in group B & 7.78 & \pm 0.34 & \\
\hline Post-vas score in group B & 3.26 & \pm 0.21 & \\
\hline
\end{tabular}

Table-I. Pre and post vas pain score in group A and $B$.

Out of 35 patients in group A mean pre and post SF36 BP score in our study was $24.18 \pm 3.81$ and $65.54 \pm 6.14$ respectively. Similarly, out of 35 patients in group B mean pre and post SF36 BP score in our study was $34.29 \pm 4.91$ and $68.21 \pm 5.87$ respectively. P-value was 0.25 . As shown in Table-Il.

\begin{tabular}{|l|c|c|c|}
\hline Variable & Mean & $\begin{array}{c}\text { Standard } \\
\text { Deviation }\end{array}$ & $\begin{array}{c}\text { P- } \\
\text { Value }\end{array}$ \\
\hline Pre-sf36 BP score in group A & 24.18 & +3.81 & \\
\hline Post- sf36 BP score in group A & 65.54 & \pm 6.14 & \multirow{2}{*}{0.25} \\
\hline Pre- sf36 BP in group B & 34.29 & +4.91 & \\
\hline Post- sf36 BP score in group B & 68.21 & \pm 5.87 & \\
\hline
\end{tabular}

Table-II. Pre and post SF36 BP score in group A and B.

In Group A, $85.7 \%$ of patients were male and $14.3 \%$ were female. However, in group B $80 \%$ of patients were male and $20 \%$ were female.

In Group A, $40 \%$ and $60 \%$ of patients were in age group 25-40 years and 41-55 years respectively. Whereas, in Group B, $48.6 \%$ and $51.4 \%$ of patients 
were in age group 25-40 years and $41-55$ years respectively.

Frequency distribution of duration of symptoms showed that in Group A $22.9 \%$ and $77.1 \%$ had the symptoms for $<2$ weeks and $>2$ weeks respectively. Whereas, in Group B, 48.6\% and $51.4 \%$ had the symptoms for $<2$ weeks and $>2$ weeks respectively.

Frequency distribution of affected side of leg showed that in Group A, 42.9\% and $57.1 \%$ had right and left side affected, respectively. Whereas, in Group B, $28.6 \%$ and $71.4 \%$ had right and left side affected, respectively. As in Figure-1.

Frequency distribution of level of herniated disc showed that in Group A, 77.1\% and 22.9\% had L4-5 and L5-S1 level of herniated disc, respectively. In Group B, 68.6\% and 31.4\% had L4-5 and L5-S1 level of herniated disc, respectively. As in Figure-2

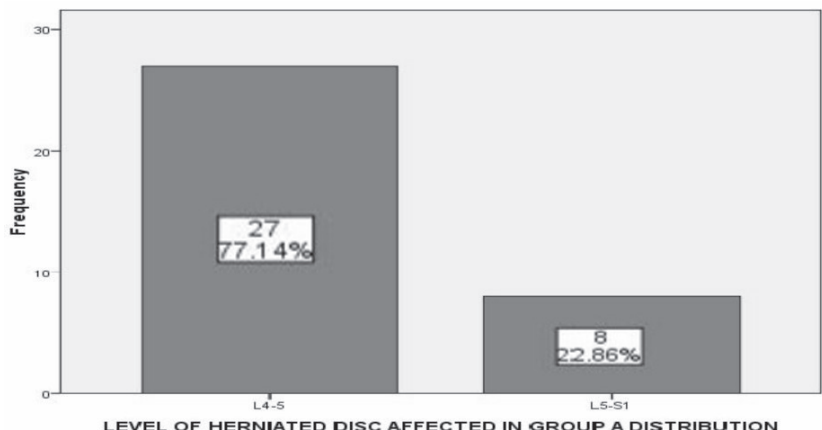

Figure-1

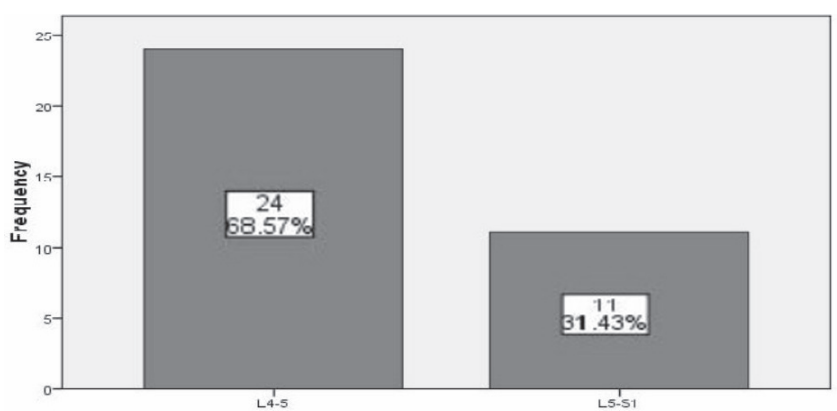

LEVEL OF HERNIATED DISC AFFECTED IN GROUP B DISTRIBUTION

Figure-2

Stratification for gender with respect to VAS pain score showed that in the male group $A$, pre and post VAS pain score were $6.97 \pm 1.25$ and
$1.54 \pm 0.45$ respectively. Similarly in the male group $B$, pre and post VAS pain score were $7.24 \pm 1.65$ and $1.78 \pm 0.54$ respectively. P-value was 0.01 . Stratification for gender with respect to VAS pain score showed that in the female group A, pre and post VAS pain score were $7.65 \pm 1.84$ and $2.25 \pm 0.28$ respectively. Similarly in the female group $B$, pre and post VAS pain score were $8.51 \pm 1.21$ and $4.87 \pm 1.07$ respectively. P-value was 0.24. As presented in Table-III.

\begin{tabular}{|c|c|c|c|c|c|}
\hline \multirow[t]{2}{*}{ Gender } & \multicolumn{2}{|c|}{$\begin{array}{c}\text { Pre and post VAS } \\
\text { score group A }\end{array}$} & \multicolumn{2}{|c|}{$\begin{array}{c}\text { Pre and post VAS } \\
\text { score group B }\end{array}$} & \multirow[t]{2}{*}{ P-Value } \\
\hline & Pre & Post & Pre & Post & \\
\hline Male & 6.97 & 1.54 & 7.24 & 1.78 & 0.01 \\
\hline Female & 7.65 & 2.25 & 8.51 & 4.87 & 0.24 \\
\hline
\end{tabular}

Table-III. Pre and post VAS score according to gender.

Stratification for gender with respect to SF36 BP score showed that in the male group A, pre and post SF36 BP score were 24.88 \pm 7.21 and $66.34 \pm 14.65$ respectively. Similarly in the male group B, pre and post SF36 BP score were $33.23 \pm 7.61$ and $67.18 \pm 13.44$ respectively. P-value was 0.00 . Stratification for gender with respect to SF36 BP score showed that in the female group A, pre and post SF36 BP score were $24.76 \pm 6.56$ and $65.77 \pm 17.83$ respectively. Similarly in the female group B, pre and post SF36 BP score were $35.18 \pm 6.91$ and $64.09 \pm 13.12$ respectively. P-value was 0.10 .As presented in Table-IV.

\begin{tabular}{|c|c|c|c|c|c|}
\hline \multirow{2}{*}{ Gender } & \multicolumn{2}{|c|}{$\begin{array}{c}\text { Preand post SF36 } \\
\text { BP score groupA }\end{array}$} & $\begin{array}{r}\text { Pre and post SF } \\
\text { 36 BP score } \\
\text { group B }\end{array}$ & P-Value \\
\cline { 2 - 5 } & Pre & Post & Pre & Post & \\
\hline Male & 24.88 & 66.34 & 33.23 & 67.18 & 0.00 \\
\hline Female & 24.76 & 65.77 & 35.18 & 64.09 & 0.10 \\
\hline
\end{tabular}

Stratification for age, duration of symptoms and side of leg with respect to VAS pain score and SF36 BP score were found to be statistically insignificant. 


\section{DISCUSSION}

Sciatica is one of the most crippling form of low back pain, with a lifetime incidence of $\square 30 \%$. It is the result of mechanical compression or irritation of one of the lumbar nerve roots. Its symptoms normally include pain, sensory and / or motor dysfunction. Leg pain is generally unilateral and is usually more than associated low back pain and specifically radiates below the knee. There may be territorial sensory and / or motor neurological deficits related to the nerve root involved. Individuals having sciatic pain if compared with people with localized low back pain only, have usually greater persistence as well as severity of pain. These individuals utilize greater healthcare resources and generally are disable and absent from work for a prolong period of time.

Out of a total of 70 patients presenting visiting Department of Neurosurgery, Civil Hospital, Karachi were included in this study. Mean age in group A and B was 45.18 \pm 7.64 and $42.78 \pm 5.87$ years respectively. $30(85.7 \%)$ were male and 05 $(14.3 \%)$ were female in group A. $28(80 \%)$ were male and $07(20 \%)$ were female were female in group $B$. Mean pre and post VAS score in group $A$ was $(7.18 \pm 0.71$ and $2.18 \pm 0.55)$ and group $B$ was $(7.78 \pm 0.34$ and $3.26 \pm 0.21)$. Mean pre and post SF36 BP score in in group A was $(24.18 \pm 3.81$ and $65.54 \pm 6.14)$ and group $B$ was $(34.29 \pm 4.91$ and 68.21 \pm 5.87 ).

A meta-analysis of 19 articles having 2272 participants in which such patients compared with conservative treatment, surgical treatment was found to be more successful in decreasing pain, ameliorating function and improving quality of life. No statistically notable dissimilarity was noticed in adverse events. ${ }^{13}$

A study from Netherland in which 283 patients were randomly distributed into early surgery vs prolonged conservative treatment concludes that the first year end results were comparable for patients allocated to early surgery and those designated to prolong conservative treatment with ultimate surgery if required, but the speed of pain remission and of perceived recovery were quick for patients grouped into early surgery. ${ }^{14}$
In another concurrent prospective randomized and observational cohort study, it was concluded that prudently chosen patients who went through operation for a lumbar disc herniation accomplished substantial amelioration than conservatively treated patients; there was very small to no degradation of outcomes in either group (operative and conservative) from 4 to 8 years. ${ }^{15}$

Surgical management of sciatica in patients when compared with prolonged conservative treatment showed improvement in functional status.

\section{CONCLUSIONS}

Many patients are willing to undergo conservative treatment for sciatica, despite of ongoing pain because of their reservation about surgery but given the results of this study, early surgical intervention is superior to medical management for sciatica regarding patient outcome. The insufficiency of data does not substantiate the selection of suitable time in our contemporary recommendations. Further studies on large scale will provide the answer for selection of patients for surgery versus conservative treatment. Furthermore, financial and economic analysis should be done for possible quick recovery versus cost and complications associated with surgery. Although surgeons may select management options on individual case, data should be evaluated for the method of selection of procedure by various surgeons as there may be a possibility of conflict of interest for surgeons who regularly operate those patients who may benefit from conservative care. Future long-term prospective, multi-center studies are needed to solve these issues.

Copyright $\odot 09$ Apr, 2020.

\section{REFERENCES}

1. Lewis $\mathrm{R}$, Williams $\mathrm{NH}$, Sutton $\mathrm{AJ}$, Burton $\mathrm{K}$, Din $\mathrm{N}$, Matar HE, et al. Comparative clinical effectiveness of management strategies for sciatica: Systematic review and network meta-analyses. Spine J. 2015 Jun 1; 15(6):1461-77. doi: 10.1016/j.spinee.2013.08.049. 
2. Jacobs $W C H$, van Tulder $M$, Arts $M$, Rubinstein SM, van Middelkoop $M$, Ostelo $R$, et al. Surgery versus conservative management of sciatica due to lumbar herniated disc: A systematic review. Eur Spine J. 2011 Apr; 20(4):513-22.

3. Ropper AH, Zafonte RD. Sciatica. N Engl J Med. 2015 Mar 26; 372(13):1240-8. doi: 10.1056/NEJMra1410151.

4. Valat JP, Genevay S, Marty M,Rozenberg S, Koes B. Sciatica. Best Pract Res Clin Rheumatol. 2010 Apr; 24(2):241-52. doi: 10.1016/j.berh.2009.11.005.

5. Jordan JL, Konstantinou K, Dowd JO. Herniated lumbar disc. BMJ Clin Evid. 2011; 06:1118.

6. Jacobs $\mathrm{WCH}$, Sidney MR, Paul CW, Wouter AM, Ferran $\mathrm{P}$, Cumhur FO, et al. The evidence on surgical interventions for low back disorders, an overview of systematic reviews. Eur Spine J. 2013 Sep; 22(9):193649.

7. Kovacs FM, Urrutia G, Alarcon JD. Surgery versus conservative treatment for symptomatic lumbar spinal stenosis: A systematic review of randomized controlled trials. Spine (Phila $\mathrm{Pa}$ 1976). 2011 Sep 15; 36(20):E1335-51. doi: 10.1097/ BRS.0b013e31820c97b1.

8. Lurie JD, Tosteson TD, Tosteson AN, Zhao W, Morgan TS, Abdu WA, et al. Surgical versus non-operative treatment for lumbar disc herniation: Eight-year results for the spine patient outcomes research trial. Spine (Phila Pa 1976). 2014 Jan 1; 39(1):3-16.
9. Alentado VJ, Lubelski D, Steinmetz MP, Benzel EC, Mroz TE. Optimal duration of conservative management prior to surgery for cervical and lumbar radiculopathy: A literature review. Global Spine J. 2014; 04(04):27986.

10. Sedighi M, Haghnegahdar A. Lumbar disc herniation surgery: Outcome and predictors. Global Spine J. 2014 Dec; 4(4):233-44. doi: 10.1055/s-0034-1390010.

11. Lequin MB, Verbaan D, Jacobs WCH, Brand R, Bouma GJ, Vandertop WP, et al. Surgery versus prolonged conservative treatment for sciatica: 5-year results of a randomized controlled trial. BMJ Open. 2013; 3(5):e002534.

12. RAND Health (US). 36-Item Short Form Survey (SF36) [Internet]. [cited 2016 Oct 20]. Available from: http://www.rand.org/health/surveys_tools/mos/36-itemshort-form.html

13. Chen BL, Guo JB, Zhang HW, Zhang YJ, Zhu Y, Zhang $J$ et al. Surgical versus non-operative treatment for lumbar disc herniation: A systematic review and meta-analysis. Clin Rehabil. 2018 Feb; 32(2):146-160.

14. Peul WC, van Houwelingen $H C$, van den Hout WB, Brand R, Eekhof JA, Tans JT et al. Surgery versus prolonged conservative treatment for sciatica. $\mathrm{N}$ Engl J Med. 2007 May 31; 356(22):2245-56.

15. Lurie JD, Tosteson TD, Tosteson AN, Zhao W, Morgan TS, Abdu WA, et al. Surgical versus non-operative treatment for lumbar disc herniation: Eight-year results for the spine patient outcomes research trial. Spine (Phila Pa 1976). 2014 Jan 1; 39(1):3-16.

\begin{tabular}{|c|c|c|c|}
\hline \multicolumn{4}{|c|}{ AUTHORSHIP AND CONTRIBUTION DECLARATION } \\
\hline Sr. \# & Author(s) Full Name & Contribution to the paper & Author(s) Signature \\
\hline 1 & Urooj Fatimah Siddiqui & Study design. & \\
\hline 2 & Muhammad Faiq Ali & Introduction. & \\
\hline 3 & M. Asim Khan Rehmani & $\begin{array}{l}\text { Data collection, analysis } \\
\text { interpretation. }\end{array}$ & \\
\hline 4 & Atiq Ahmed Khan & $\begin{array}{l}\text { Proof reading and research } \\
\text { plan. }\end{array}$ & \\
\hline 5 & Sheeraz Ahmed Ghori & $\begin{array}{l}\text { Data analysis, sample } \\
\text { collection. }\end{array}$ & Shever \\
\hline 6 & Qazi M. Zeeshan & $\begin{array}{l}\text { Data analysis, sample } \\
\text { collection. }\end{array}$ & \\
\hline 7 & M. Imran & Research plan and supervision. & \\
\hline
\end{tabular}

